\title{
Inhomogeneity in response to air pollution in European children (PEACE project)
} Willem Roemer, Jocelyne Clench-Aas, Norbert Englert, Gerard Hoek, Klea Katsouyanni,
Juha Pekkanen, Bert Brunekreef based sample the subjects rarely did. In another panel study by Pope and Dockery ${ }^{2}$ a sample selected on the basis of asthmatic symptoms but no use of medication reacted more strongly than an asymptomatic sample. Peters et al showed that use of medication attenuated the associations between sulphate concentrations and respiratory health. ${ }^{3}$ Besides the use of medication other factors are related to the response of a child to air pollution. In a study by Roemer et $a l^{4}$ children selected on asthmatic attacks in the previous year had a stronger association between increases in $\mathrm{PM}_{10}$ or sulphur dioxide $\left(\mathrm{SO}_{2}\right)$ and decreased peak expiratory flow (PEF) than children selected on chronic cough. Timonen and Pekkanen reported differences in association between $\mathrm{PEF}$, respiratory symptoms, and $\mathrm{PM}_{10}$, black smoke (BS), $\mathrm{SO}_{2}$, and nitrogen dioxide $\left(\mathrm{NO}_{2}\right)$ in subgroups of children selected on cough or on asthmatic symptoms in the Finnish PEACE panel. ${ }^{5}$ Pershagen et al showed a relation between wheezing bronchitis and chronic exposure to outdoor concentrations of $\mathrm{NO}_{2}$ in girls but not in boys. ${ }^{6}$ Brunekreef et al reported that the association between lung function and chronic exposure to air pollution assessed as lorry traffic density was stronger in girls than in boys. Atopy and lung function were related to variability of $\mathrm{PEF}^{8}$ and the prevalence of acute respiratory symptoms, ${ }^{9}$ so it might be that children with an atopic constitution or a lower lung function react differently to air pollution compared with non-atopic children or children with a better lung function. To our knowledge, in epidemiological panel studies objective data to characterise subjects (such as skin prick tests) have not been evaluated with respect to the response to air pollution.

The pollution effects on asthmatic children in Europe (PEACE) study was designed to study the relation between short term changes in air pollution and lung function, respiratory symptoms, and use of medication. It is a collection of panel studies that were conducted in the winter of 1993-94 in 14 different centres in Europe. In that paper the PEACE data were stratified to investigate if subgroups within the panels, based on predefined characteristics, reacted differently to short term changes in air pollution. In the complete panels no consistent association between air pollution and respiratory health was found. ${ }^{10}$ In this paper we evaluate whether potentially more sensitive subgroups (using predefined characteristics) in the panels did show effects of air pollution. Specifically we hypothesised that children selected on asthma symptoms but not using

\begin{abstract}
the patient based sample the subjects usually used asthma medication whereas in the school

There are indications that some groups of chillution between respiratory health and air polcut off aerodynamic diameter of $10 \mu \mathrm{m}\left(\mathrm{PM}_{10}\right)$ to be stronger in school children selected on respiratory symptoms by a screening questiondiagnosed asthma. It was hypothesised that this difference was caused by management of respi-
ratory health by use of medication, because in
\end{abstract}


medication; children with atopy; children with low baseline lung function; and girls reacted more strongly to air pollution than did the complete panel.

\section{Materials and methods} PEACE STUDY

The PEACE study is a collaboration of 14 European centres (appendix). All centres used the same protocol for data collection and data analysis. Design, methods, and results of the individual panels ${ }^{11}$ as well as combined effect estimates for the complete panels have been reported elsewhere. ${ }^{10}$ Each centre selected two panels, one panel in an urban area and one in a suburban or rural area (called here suburban panel). The suburban panel was selected from a community which had no major traffic emissions, had no large industrial sources, had sufficient size to select enough subjects and was close to a site of an existing air pollution measurement network. Suburban panels were included to evaluate differences in effects of air pollution caused by level and composition of air pollution, in panels paired by meteorological characteristics. The subject selection and characterisation were somewhat different in Hettstedt. Therefore, in this paper the data from Hettstedt are excluded.

Children aged between 6 and 12 years with chronic respiratory symptoms were selected by a screening questionnaire completed by parents. The criteria for selection were: reporting recent wheeze (apart from colds), recent attacks of shortness of breath with wheezing, recent dry cough (apart from colds), or asthma ever diagnosed by a doctor. To further characterise the children, atopy was assessed by skin prick test, and pulmonary function was assessed by forced expiratory manoeuvres. Skin prick tests were carried out with the ALK system (ALK laboratories, Horsholm, Denmark). A common set of four single allergens was used for all areas which covered the most important allergens in the participating countries. These allergens were house dust mite (Dermatophagoides pteronyssinus), cat fur, and pollen of timothy grass (Phleum pratense) and birch (Betula verrucosa). A positive control (histamine) and a negative control (diluent) were applied in each test. Two locally important allergens were added by each individual centre. ${ }^{11} \mathrm{~A}$ child was considered atopic if there was a wheal reaction of $>2 \mathrm{~mm}$ on one of the tested allergens together with a negative control $\leqslant 1 \mathrm{~mm}$ and a positive control of $>0$ $\mathrm{mm}$. Forced expiratory manoeuvres were performed with the protocol of the European Community for Coal and Steel (ECCS). ${ }^{12}{ }^{13}$ The equipment used in the centres was not identical but had to fulfil the technical requirements of the ECCS. Selection of values was according to the ECCS. ${ }^{12}{ }^{13}$ The measured values were expressed as a percentage of the predicted values calculated from the reference equations given in Quanjer et al. ${ }^{14}$

Peak expiratory flow (PEF) was measured each day in the morning and in the evening for at least 2 months. All centres used the mini Wright peak flowmeter. A parent completed a daily diary for the child recording the presence and severity of respiratory symptoms and use of medication for respiratory symptoms.

Concurrent air pollution measurements were performed in both the urban and suburban locations. Daily 24 hour measurements of $\mathrm{PM}_{10}, \mathrm{BS}, \mathrm{SO}_{2}$, and $\mathrm{NO}_{2}$ were made at sites not influenced by nearby sources, so were called background sites. More information about the measurement methods is given elsewhere. ${ }^{11} 15$

\section{STATISTICAL METHODS}

Our analytical approach consisted of the calculation of the association between air pollution and respiratory health in the subgroups already defined within the individual panels. Next, the regression slopes calculated for the individual panels were combined to obtain an average slope in the subgroups - such as children with and without atopy. To avoid large changes in day to day composition of the reporting group, children were included in the analysis if they had valid PEF measurements and respiratory symptoms on $>60 \%$ of the days. Also, only children with no missing information on sex, skin prick testing, lung function testing, and with a positive response to one of the screening questions were included to avoid differences in the total number of children in the different subgroup analyses. Subgroups were defined on the basis of use of medication, selection question, sex, atopy, and lung function. Atopy subgroups were based on the skin prick test results. Lung function subgroups were made by dividing the values expressed as percentage of predicted maximal mid expiratory flow (MMEF) or forced expiratory volume in $1 \mathrm{sec}-$ ond $\left(\mathrm{FEV}_{1}\right)$ into quartiles. To avoid subjects with different lung function levels being categorised in the same group, quartiles were calculated over the whole group, independently of centre. To increase the contrast, the children with the worst lung function were compared with the children with a normal lung function. More specifically, a comparison was made between the subjects in the lowest quartile $v$ the subjects above the median. Three subgroups based on use of medication and selection questionnaire were made: selected on asthmatic symptoms (wheeze or asthma diagnosis) and use of respiratory medication $\left(\mathrm{AST}^{+}\right)$, and no respiratory medication $\left(\mathrm{AST}^{-}\right.$), and a third group selected only on the question on nightly coughing but no medication $\left(\operatorname{cough}^{-}\right)$. Medication was defined as the use of bronchodilators - such as salbutamol, albuterol, fenoterol, terbutaline-or maintenance or preventive medication-such as cromolyn, theophylline, antihistamine, or corticosteroid-on any day during the study period. There were few subjects selected only on the question on nightly coughing and use of medication $(n=23)$, so these were left out in this subgroup analysis.

The association between PEF and concentrations of air pollutants was calculated by linear regression for each child separately. This analysis included correction for first order autocorrelation in the residuals. In the subgroups the dis- 
tribution of these individual coefficients was studied next. To correct for subject characteristics, weighted multiple linear regression was performed with the individual coefficients as the dependent variables and subgroup indicators as independent variables, with the weights being the inverse of the variance of the individual coefficients. Cook's distance was calculated to evaluate the influence of each observation. ${ }^{16}$ Observations with extreme values $(>1.0)$ for Cook's distance were deleted to test the stability of the calculated slopes.

The symptoms in the diaries were recoded to 0 (no symptom) and 1 (slight, moderate or severe symptom) and daily prevalence was calculated within subgroups. All panels were analysed separately. Daily prevalence within a subgroup was defined as the fraction of children for whom the presence of a respiratory symptom or use of medication was reported from those children who provided valid diary data for that symptom on that day within that subgroup. The association between subgroup specific symptom prevalence and air pollution was evaluated with logistic regression but under the assumption of normally distributed residuals. This was done because when analysing prevalence with binomial distributed residuals the residuals showed substantial underdispersion. The observations were weighted by the number of reporting children within a subgroup on each day. Correction for autocorrelation of residuals was made assuming a first order autoregressive structure. The respiratory symptoms cough, phlegm, combined upper respiratory symptoms (runny or stuffy nose or sore throat), and lower respiratory symptoms (shortness of breath, wheeze, asthma attacks) were analysed. The prevalence of use of bronchodilators was also analysed.
The regression slopes of the components of air pollution from the logistic regression models of the separate panels were used to calculate a combined effect estimate for each subgroup. To avoid calculations being based on few subjects or few reported symptoms which could lead to extreme effect estimates, data from a subgroup of a specific panel were only included if they consisted of more than five subjects and had a mean prevalence $>3 \%$. A combined fixed effect estimate was calculated as the weighted mean of the subgroup specific slopes with the weights being the inverse of the variance of the slope. The standard error (SE) of the combined slope was calculated as the inverse of the square root of the sum of the weights. Heterogeneity of subgroup specific slopes was evaluated by a $\chi^{2}$ test for homogeneity. ${ }^{17}$ In the case of homogeneity the combined slope calculated as a fixed effect was considered to be an appropriate estimate. A conservative cut off point of a $p$ value $<0.25$ was chosen to determine heterogeneity. In the case of heterogeneity $(p<0.25)$ combined effect estimates with random effect estimation were calculated. ${ }^{17}$ The combined effect estimate was expressed as an odds ratio (OR) for a $100 \mu \mathrm{g} / \mathrm{m}^{3}$ increase in air pollution.

The explanatory variables for PEF as well as symptom prevalence were 24 hour average concentrations of $\mathrm{PM}_{10}, \mathrm{BS}, \mathrm{SO}_{2}$, and $\mathrm{NO}_{2}$, analysed separately because of the high correlation $(r>0.6)$ between pollutants. Current day concentration (lag 0), previous day concentration (lag 1), concentration of 2 days before (lag 2 ), and the average of lag 0-6 days (7 day mean) were analysed separately. Minimum temperature, a dummy variable indicating normal school days versus holidays or weekends and time trend were included as possible confounders in PEF as well as prevalence analysis. Time trend was included in the prevalence

Table 1 Characteristics of subjects included by panel

\begin{tabular}{|c|c|c|c|c|c|c|c|}
\hline & & Subjects $n$ & $\begin{array}{l}\text { Atopic* } \\
n(\%)\end{array}$ & $\begin{array}{l}\text { MMEFt quartile } \\
n(\%)\end{array}$ & $\begin{array}{l}\text { Cough } \neq \\
n(\%)\end{array}$ & $\begin{array}{l}A S T^{+} \neq \\
n(\%)\end{array}$ & $\begin{array}{l}A S T \neq \\
n(\%)\end{array}$ \\
\hline \multirow[t]{2}{*}{ Umeå (Sweden) } & Urban & 72 & $40(56)$ & $27(38)$ & $11(15)$ & $25(35)$ & $36(50)$ \\
\hline & Suburban & 69 & $43(62)$ & $21(30)$ & $10(15)$ & $36(52)$ & $23(33)$ \\
\hline \multirow{2}{*}{ Malmö (Sweden) } & Urban & 64 & $31(48)$ & $22(34)$ & $15(23)$ & $22(34)$ & $25(39)$ \\
\hline & Suburban & 69 & $38(55)$ & $21(30)$ & $21(30)$ & $19(28)$ & $28(41)$ \\
\hline \multirow[t]{2}{*}{ Kuopio (Finland) } & Urban & 85 & $53(62)$ & $24(28)$ & 45 (53) & $11(13)$ & $28(33)$ \\
\hline & Suburban & 82 & $49(60)$ & $14(17)$ & $44(54)$ & $14(17)$ & $21(26)$ \\
\hline \multirow[t]{2}{*}{ Oslo (Norway) } & Urban & 40 & $19(48)$ & $11(28)$ & $6(15)$ & $8(20)$ & $26(65)$ \\
\hline & Suburban & 49 & $27(55)$ & $13(27)$ & $7(14)$ & $18(37)$ & $24(49)$ \\
\hline \multirow{2}{*}{ Amsterdam (The Netherlands) } & Urban & 52 & $27(52)$ & $14(27)$ & $18(35)$ & $11(21)$ & $23(44)$ \\
\hline & Suburban & 61 & $23(38)$ & $18(30)$ & $27(44)$ & $13(21)$ & $21(34)$ \\
\hline \multirow[t]{2}{*}{ Berlin (Germany) } & Urban & 46 & $28(61)$ & $23(50)$ & $2(4)$ & $14(30)$ & $30(65)$ \\
\hline & Suburban & 57 & $34(60)$ & $23(40)$ & $2(4)$ & $11(19)$ & $44(77)$ \\
\hline \multirow{2}{*}{ Katowice (Poland) } & Urban & 68 & $33(49)$ & $22(32)$ & $24(35)$ & $3(4)$ & $40(59)$ \\
\hline & Suburban & 71 & $21(30)$ & $26(37)$ & $10(14)$ & $6(9)$ & $54(76)$ \\
\hline \multirow[t]{2}{*}{ Cracow (Poland) } & Urban & 42 & $3(7)$ & $9(21)$ & $21(50)$ & $2(5)$ & $19(45)$ \\
\hline & Suburban & 60 & $32(53)$ & $4(7)$ & $20(33)$ & $10(17)$ & $29(48)$ \\
\hline \multirow[t]{2}{*}{ Teplice (Czech Republic) } & Urban & 75 & $12(16)$ & $9(12)$ & $44(59)$ & $3(4)$ & $27(36)$ \\
\hline & Suburban & 75 & $20(27)$ & $5(7)$ & $25(33)$ & $15(20)$ & $34(45)$ \\
\hline \multirow[t]{2}{*}{ Prague (Czech Republic) } & Urban & 66 & $32(49)$ & $25(38)$ & $1(2)$ & $19(29)$ & $46(70)$ \\
\hline & Suburban & 68 & $55(81)$ & $24(35)$ & $4(6)$ & $29(43)$ & $30(44)$ \\
\hline \multirow[t]{2}{*}{ Budapest (Hungary) } & Urban & 67 & $27(40)$ & 9 (13) & $29(43)$ & $10(15)$ & $28(42)$ \\
\hline & Suburban & 58 & $34(59)$ & $8(14)$ & $18(31)$ & $5(9)$ & $34(59)$ \\
\hline \multirow[t]{2}{*}{ Pisa (Italy) } & Urban & 44 & $35(80)$ & $11(25)$ & $0(0)$ & $16(36)$ & $28(64)$ \\
\hline & Suburban & 48 & $27(56)$ & $5(10)$ & $8(17)$ & $14(29)$ & $25(52)$ \\
\hline \multirow{2}{*}{ Athens (Greece) } & Urban & 68 & $12(18)$ & $7(10)$ & $31(46)$ & $8(12)$ & $26(38)$ \\
\hline & Suburban & 65 & $15(23)$ & $8(12)$ & $14(22)$ & $17(26)$ & $29(45)$ \\
\hline Total & & 1621 & 770 (48) & $405(25)$ & $457(28)$ & 359 (22) & $778(48)$ \\
\hline
\end{tabular}

${ }^{\star}$ Children with one or more positive skin prick test reactions. †Children in lowest MMEF quartile. $¥$ Children selected on nightly coughing only, no medication used during study period $\left(\mathrm{Cough}^{-}\right)$; selected on asthma question, no medication use during study period (AST); selected on asthma question, and did use medication during study period $\left(\mathrm{AST}^{+}\right)$. 
analysis as a linear, quadratic, and cubic term to correct for long term time trends. In the PEF analysis time trend was included as a square root and a linear term to correct for a possible training effect and lung growth, respectively.

\section{Results}

The characteristics of the subjects included are presented in table 1 by panel. The percentage of atopic children within the panels ranges from $7 \%$ in the urban location of Cracow to $81 \%$ in the suburban location of Prague. Also the prevalence of positive responses on the selection questions show a wide range. These differences probably reflect the slight modifications in selection procedure which some centres made during the fieldwork.

A wide range of concentrations of air pollution was included, from low concentrations of both gaseous and particulate components in Scandinavia, higher concentrations in western Europe and the highest concentrations in central and southern Europe. Mean concentrations during the study period for $\mathrm{PM}_{10}$ ranged from $11.2 \mu \mathrm{g} / \mathrm{m}^{3}$ (Oslo, suburban) to 98.8 $\mu \mathrm{g} / \mathrm{m}^{3}$ (Athens, urban), for BS from $4.5 \mu \mathrm{g} / \mathrm{m}^{3}$ (Malmö, suburban) to $109.2 \mu \mathrm{g} / \mathrm{m}^{3}$ (Athens, urban), for $\mathrm{SO}_{2}$ from $2.7 \mu \mathrm{g} / \mathrm{m}^{3}$ (Umeå, urban) to $113.9 \mu \mathrm{g} / \mathrm{m}^{3}$ (Prague, urban), and for $\mathrm{NO}_{2}$ from $8.9 \mu \mathrm{g} / \mathrm{m}^{3}$ (Malmö, suburban) to 74.9 $\mu \mathrm{g} / \mathrm{m}^{3}$ (Athens, urban). More information about the concentrations of air pollutants is published elsewhere. ${ }^{15}$

ASSOCIATION BETWEEN AIR POLLUTION AND PEF Table 2 shows the median of regression coefficients of air pollution representations on evening PEF in the subgroups. There was no consistent pattern of differences in reaction to air pollution between the subgroups based on sex, atopy, or lung function. Regression analysis, including all subgroup indicators simultaneously, confirmed this pattern.
Table 2 also shows that the median coefficients in the $\mathrm{AST}^{+}$group were positive for all components with significant median coefficients for BS 7 day mean, $\mathrm{SO}_{2}$ lag 0 , lag 1, 7day mean, and $\mathrm{NO}_{2}$ lag 1 . On the other hand, most of the median coefficients in the cough ${ }^{-}$group were negative, with $\mathrm{PM}_{10}$ lag 1 reaching significance. The median coefficients of the $\mathrm{AST}^{-}$ group were generally positive but none of the coefficients differed significantly from zero. Restriction of the data to the centres with the highest mean prevalence of use of bronchodilators in the $\mathrm{AST}^{+}$group (Berlin (Germany), Prague (Czech Republic), Malmö and Umeå (Sweden), Pisa (Italy), Athens (Greece), Amsterdam (the Netherlands)) showed that the median coefficients of the AST ${ }^{+}$group became more positive and increased in significance. Median coefficients of the $\mathrm{AST}^{+}$group in the other centres no longer differed consistently from zero.

The median coefficients on morning PEF showed the same pattern for the subgroups based on the selection questionnaire and use of medication but the effect was less pronounced. There was no clear pattern within any of the other stratifications of the individual coefficients on morning PEF (not presented).

ASSOCIATION BETWEEN AIR POLLUTION AND PREVALENCE OF SYMPTOMS AND USE OF MEDICATION

The effect estimates of air pollution on prevalence of upper respiratory symptoms, lower respiratory symptoms, and use of medication of the subgroups based on atopy are in table 3. Most ORs were $<1.00$, some of these were even significant, mostly for upper respiratory symptoms in the non-atopic group. The few ORs $>1.00$ were not significant. No consistent significant association with air pollution could be detected in the subjects with or without atopy. Also the prevalences of cough and phlegm did not show consistent associa-

Table 2 Median individual coefficients in subgroups of total PEACE study population (coefficients expressed as l/min change in evening PEF per 100 $\mu g / m^{3}$ increase in air pollutant)

\begin{tabular}{|c|c|c|c|c|c|c|c|c|c|c|c|}
\hline & \multirow{2}{*}{\multicolumn{2}{|c|}{ Sex }} & \multirow{2}{*}{\multicolumn{2}{|c|}{ Atopy }} & \multirow{2}{*}{\multicolumn{3}{|c|}{ Selection and medication }} & \multicolumn{4}{|c|}{ Lung function } \\
\hline & & & & & & & & \multicolumn{2}{|l|}{$M M E F$} & \multicolumn{2}{|l|}{$F E V_{1}$} \\
\hline & Boy & Girl & - & + & Cough $^{-}$ & $A S T^{-}$ & $A S T^{+}$ & $\begin{array}{l}\text { Lowest } \\
\text { quartile }\end{array}$ & $\begin{array}{l}\text { Above } \\
\text { median }\end{array}$ & $\begin{array}{l}\text { Lowest } \\
\text { quartile }\end{array}$ & $\begin{array}{l}\text { Above } \\
\text { median }\end{array}$ \\
\hline \multicolumn{12}{|l|}{$\mathrm{PM}_{10}:$} \\
\hline Lag 0 & 1.1 & -0.5 & -0.1 & $0.8+$ & -0.9 & 0.7 & 1.6 & -0.1 & -0.1 & 0.6 & 0.3 \\
\hline Lag 1 & -0.5 & -0.9 & -0.8 & -0.4 & $-1.3 \ddagger$ & -0.3 & 0.0 & $-1.4 \dagger$ & -0.5 & -0.7 & $-0.9^{\star}$ \\
\hline Lag 2 & -0.5 & $1.2^{\star} \ddagger$ & $0.4 \dagger$ & 0.2 & 0.0 & 0.2 & 2.1 & -0.4 & 0.4 & 0.6 & -0.1 \\
\hline 7 Day mean & 0.1 & $1.0^{\mathrm{T}}$ & 0.5 & 0.6 & -0.9 & 1.7 & 1.2 & 0.1 & -0.4 & $2.6+$ & $-0.9 \ddagger$ \\
\hline \multicolumn{12}{|l|}{ Black smoke: } \\
\hline Lag 0 & $0.7 \dagger$ & 0.2 & -0.2 & $1.5 \dagger$ & -0.3 & 0.2 & $2.6+\ddagger$ & 0.3 & 0.6 & 0.0 & $1.2 \dagger$ \\
\hline Lag 1 & 0.9 & -0.3 & 0.2 & 0.6 & -1.3 & 0.4 & 2.4 & -0.9 & 1.8 & 0.3 & 0.3 \\
\hline Lag 2 & 0.2 & 0.1 & -0.2 & 0.6 & -0.9 & 0.2 & $2.3 \dagger$ & -2.0 & 0.1 & -0.2 & 0.1 \\
\hline 7 Day mean & 2.5 & 2.0 & 1.8 & 2.7 & -1.2 & 2.5 & $10.3^{\star} \ddagger$ & 2.7 & 1.5 & 4.3 & 2.5 \\
\hline \multicolumn{12}{|l|}{$\mathrm{SO}_{2}:$} \\
\hline Lag 0 & $1.9^{\star}$ & 1.4 & 0.7 & $2.2 \dagger$ & 1.1 & 1.1 & $5.3^{\star}$ & 0.4 & $2.1^{\star}$ & -0.2 & $2.1^{\star} \ddagger$ \\
\hline Lag 1 & 0.8 & 0.2 & 0.3 & 1.1 & -1.1 & 0.3 & $4.5^{\star} \ddagger$ & 0.8 & 0.2 & 1.9 & 0.1 \\
\hline Lag 2 & 0.3 & 1.5 & 0.3 & 1.3 & -0.6 & 1.0 & $1.3^{\top}$ & 0.4 & $1.6+$ & 0.7 & 1.6 \\
\hline 7 Day mean & 2.7 & 0.7 & 1.4 & 3.2 & -1.3 & 2.0 & $12.1^{\star}$ & $3.2 \dagger$ & 1.4 & $4.4 \dagger$ & $3.0 \dagger$ \\
\hline \multicolumn{12}{|l|}{$\mathrm{NO}_{2}:$} \\
\hline Lag 0 & 0.9 & 0.7 & 0.3 & 1.0 & 0.0 & 0.9 & 1.9 & 0.1 & 0.8 & $2.7 \dagger$ & 0.6 \\
\hline Lag 1 & -0.3 & -0.5 & -1.1 & 0.5 & -2.0 & -0.7 & $3.3^{\star} \ddagger$ & -1.8 & -1.1 & -0.3 & -0.1 \\
\hline Lag 2 & -0.8 & 1.2 & 1.2 & -0.8 & $-1.6 \dagger$ & 0.9 & $0.9^{\top}$ & 1.0 & $-0.8 \dagger$ & 1.7 & $-0.7 \dagger \neq$ \\
\hline 7 Day mean & 0.3 & 1.5 & 1.0 & 0.2 & -1.7 & 0.5 & 5.9 & $2.6+$ & $-1.4 \dagger \neq$ & 1.9 & $-0.3 \ddagger$ \\
\hline
\end{tabular}

${ }^{\star} \mathrm{p}<0.05 ; \mathrm{tp}<0.10$, sign rank test; $\neq \mathrm{p}<0.05$ Wilcoxon rank sum or Kruskal-Wallis test to test in difference in distribution.

$\mathrm{Cough}^{-}=$selected on nightly coughing only, no medication use during study period; $\mathrm{AST}^{-}=$selected on asthma question, no medication use during study period; $\mathrm{AST}^{+}=$selected on asthma question, and did use medication during study period. 
Table 3 Combined OR (95\% CI) for $100 \mu \mathrm{g} / \mathrm{m}^{3}$ increase in air pollution on prevalence of symptoms, in subjects with and without atopy

\begin{tabular}{|c|c|c|c|c|c|c|c|c|c|c|c|c|}
\hline & \multicolumn{4}{|c|}{ Upper respiratory symptoms } & \multicolumn{4}{|c|}{ Lower respiratory symptoms } & \multicolumn{4}{|c|}{ Bronchodilator used } \\
\hline & \multicolumn{2}{|c|}{ Non-atopic } & \multicolumn{2}{|c|}{ Atopic } & \multicolumn{2}{|c|}{ Non-atopic } & \multicolumn{2}{|c|}{ Atopic } & \multicolumn{2}{|c|}{ Non-atopic } & \multicolumn{2}{|c|}{ Atopic } \\
\hline & $n^{*}$ & OR $(95 \% C I)$ & $n^{\star}$ & OR $(95 \% C I)$ & $\overline{n^{\star}}$ & OR $(95 \% C I)$ & $n^{\star}$ & OR $(95 \% C I)$ & $n^{\star}$ & OR $(95 \% C I)$ & $n^{\star}$ & OR $(95 \% C I)$ \\
\hline \multicolumn{13}{|l|}{$\mathrm{PM}_{10}$ : } \\
\hline Lag 0 & 25 & $0.94(0.86$ to 1.02$) \ddagger$ & 25 & $0.98(0.92$ to 1.04$) \dagger$ & 19 & $0.91(0.78$ to 1.06$) \ddagger$ & 23 & $1.05(0.87$ to 1.26$) \ddagger$ & 9 & $0.95(0.75$ to 1.22$) \ddagger$ & 22 & $0.96(0.89$ to 1.04$) \dagger$ \\
\hline Lag 1 & 25 & $0.92(0.87$ to 0.97$) \dagger$ & 25 & $0.99(0.93$ to 1.05$) \dagger$ & 19 & $0.96(0.83$ to 1.12$) \ddagger$ & 23 & $0.99(0.84$ to 1.17$) \ddagger$ & 9 & $1.09(0.81$ to 1.47$) \ddagger$ & 22 & $0.92(0.81$ to 1.05$) \ddagger$ \\
\hline Lag 2 & 25 & $0.95(0.88$ to 1.01$) \ddagger$ & 25 & $0.95(0.90$ to 1.01$) \dagger$ & 19 & $0.90(0.80$ to 1.01$) \dagger$ & 23 & $0.97(0.85$ to 1.11$) \ddagger$ & 9 & 1.19 (0.89 to 1.59$) \ddagger$ & 22 & $1.00(0.84$ to 1.20$) \ddagger$ \\
\hline 7 Day mean & 25 & $0.63(0.45$ to 0.86$) \ddagger$ & 25 & $0.88(0.68$ to 1.15$) \ddagger$ & 19 & $0.68(0.33$ to 1.41$) \ddagger$ & 23 & $0.89(0.50$ to 1.59$) \ddagger$ & 9 & $0.83(0.48$ to 1.43$) \dagger$ & 22 & $1.02(0.59$ to 1.76$) \ddagger$ \\
\hline \multicolumn{13}{|l|}{ Black smoke: } \\
\hline Lag 0 & 25 & $1.02(0.96$ to 1.08$) \dagger$ & 25 & $1.00(0.90$ to 1.12$) \ddagger$ & 19 & $0.86(0.76$ to 0.97$) \dagger$ & 23 & $1.09(0.88$ to 1.36$) \ddagger$ & 9 & $1.03(0.86$ to 1.22$) \dagger$ & 22 & $0.99(0.86$ to 1.14$) \dagger$ \\
\hline Lag 1 & 25 & $0.93(0.85$ to 1.02$) \ddagger$ & 25 & $0.92(0.82$ to 1.02$) \ddagger$ & 19 & $0.90(0.79$ to 1.01$) \dagger$ & 23 & $0.87(0.69$ to 1.10$) \ddagger$ & 9 & $1.00(0.64$ to 1.58$) \ddagger$ & 22 & $0.88(0.74$ to 1.06$) \ddagger$ \\
\hline Lag 2 & 25 & $0.92(0.84$ to 1.01$) \ddagger$ & 25 & $0.91(0.81$ to 1.01$) \ddagger$ & 19 & $0.93(0.76$ to 1.13$) \ddagger$ & 23 & $0.93(0.75$ to 1.16$) \ddagger$ & 9 & $1.03(0.87$ to 1.22$) \dagger$ & 22 & $1.03(0.86$ to 1.22$) \ddagger$ \\
\hline 7 Day mean & 25 & $0.57(0.39$ to 0.82$) \ddagger$ & 25 & $0.89(0.59$ to 1.32$) \ddagger$ & 19 & $0.52(0.20$ to 1.34$) \ddagger$ & 23 & $0.90(0.36$ to 2.23$) \ddagger$ & 9 & $0.94(0.35$ to 2.52$) \ddagger$ & 22 & $0.99(0.44$ to 2.20$) \ddagger$ \\
\hline \multicolumn{13}{|c|}{ (1) } \\
\hline Lag 0 & 23 & $0.86(0.76$ to 0.98$) \ddagger$ & 23 & $0.89(0.76$ to 1.04$) \ddagger$ & 17 & $0.91(0.65$ to 1.28$) \ddagger$ & 21 & 4 to 1.29$) \ddagger$ & 7 & $0.95(0.83$ to 1.09$) \dagger$ & 20 & $0.94(0.83$ to 1.07$) \dagger$ \\
\hline Lag 1 & 23 & $0.94(0.88$ to 1.01$) \dagger$ & 23 & $0.97(0.89$ to 1.06$) \dagger$ & 17 & $1.08(0.77$ to 1.51$) \ddagger$ & 21 & $0.98(0.72$ to 1.32$) \ddagger$ & 7 & $1.00(0.88$ to 1.15$) \dagger$ & 20 & 0.87 (0.69 to 1.08$) \ddagger$ \\
\hline Lag 2 & 23 & $0.96(0.89$ to 1.02$) \dagger$ & 23 & 0.81 (0.70 to 0.94$) \ddagger$ & 17 & $1.06(0.80$ to 1.41$) \ddagger$ & 21 & $0.83(0.62$ to 1.10$) \ddagger$ & 7 & $1.04(0.91$ to 1.18$) \dagger$ & 20 & $1.06(0.79$ to 1.42$) \ddagger$ \\
\hline 7 Day mean & 23 & $0.52(0.35$ to 0.78$) \ddagger$ & 23 & $0.72(0.45$ to 1.18$) \ddagger$ & 17 & $0.69(0.34$ to 1.40$) \ddagger$ & 21 & $1.09(0.50$ to 2.38$) \ddagger$ & 7 & $0.45(0.09$ to 2.11$) \ddagger$ & 20 & $0.71(0.36$ to 1.40$) \ddagger$ \\
\hline \multicolumn{13}{|l|}{$\mathrm{NO}_{2}:$} \\
\hline Lag 0 & 24 & $0.96(0.88$ to 1.05$) \dagger$ & 24 & 0.85 (0.77 to 0.94$) \dagger$ & 18 & $1.14(0.96$ to 1.35$) \dagger$ & 22 & $1.13(0.87$ to 1.47$) \ddagger$ & 9 & $0.94(0.71$ to 1.23$) \dagger$ & 22 & 0.95 (0.82 to 1.09$) \dagger$ \\
\hline Lag 1 & 24 & $0.86(0.75$ to 0.99$) \ddagger$ & 24 & $1.06(0.93$ to 1.22$) \ddagger$ & 18 & $0.77(0.60$ to 1.00$) \ddagger$ & 22 & $0.98(0.76$ to 1.27$) \ddagger$ & 9 & $1.41(0.90$ to 2.21$) \ddagger$ & 22 & $0.98(0.85$ to 1.14$) \dagger$ \\
\hline Lag 2 & 24 & $0.98(0.90$ to 1.07$) \dagger$ & 24 & $0.90(0.79$ to 1.03$) \ddagger$ & 18 & $0.79(0.60$ to 1.02$) \ddagger$ & 22 & $0.89(0.66$ to 1.21$) \ddagger$ & 9 & $0.98(0.58$ to 1.63$) \ddagger$ & 22 & $1.11(0.88$ to 1.42$) \ddagger$ \\
\hline 7 Day mean & 24 & $0.49(0.28$ to 0.85$) \ddagger$ & 24 & $1.00(0.60$ to 1.69$) \ddagger$ & 18 & $0.51(0.18$ to 1.48$) \ddagger$ & 22 & $0.82(0.28$ to 2.39$) \ddagger$ & 9 & $0.76(0.34$ to 1.69$) \dagger$ & 22 & $1.18(0.52$ to 2.68$) \ddagger$ \\
\hline
\end{tabular}

«Number of panel specific estimates; †Fixed effects model; $¥$ Random effects model.

tions with air pollution in the atopic or non-atopic subgroup (not presented).

Table 4 shows the results of the stratification on selection questions and use of medication. For prevalence of phlegm, the ORs in the cough ${ }^{-}$group were mostly $>1.00$ for $\mathrm{PM}_{10}$, BS, and $\mathrm{NO}_{2}$, but almost all were non-significant. The ORs in the other two groups were predominantly $<1.00$. For prevalence of lower respiratory symptoms the ORs were generally $<1.00$. Stratification of effect estimates on cough and symptoms of the upper respiratory tract did not show consistent differences (not presented).

The prevalence of use of bronchodilators in the $\mathrm{AST}^{+}$group was not related to any component of air pollution. For example, the ORs of $\mathrm{PM}_{10}$ were for lag 0, 0.98 (95\% confidence interval $(95 \% \mathrm{CI}) 0.89$ to 1.07$)$; lag $1,0.97$ (0.85 to 1.09$)$; lag $2,0.98$ (0.87 to 1.10$)$, and 7 day mean 1.21 (0.71 to 2.07). Restriction of the data to the centres with the highest mean prevalence of use of bronchodilators also did not show significant associations.

Figure 1 shows the ORs of lag 1 of the components of air pollution on prevalence of symptoms after stratification on percentage of predicted MMEF. The ORs of the children with a percentage of predicted MMEF above the median value are all $<1.00$, with $\mathrm{PM}_{10}$, BS, and $\mathrm{SO}_{2}$ lag 1 being significant for symptoms of the upper respiratory tract prevalence and $\mathrm{PM}_{10}, \mathrm{BS}$, and $\mathrm{NO}_{2}$ lag 1 for prevalence of symptoms of the lower respiratory tract. The children in the first quartile (low lung function) had ORs which were predominantly $>1.00$, BS lag 1 was significantly associated with cough. The ORs of lag 0 of $\mathrm{PM}_{10}, \mathrm{BS}, \mathrm{SO}_{2}$, and $\mathrm{NO}_{2}$ on symptom prevalence showed the same pattern, whereas lag 2 and 7 day did not (not presented).

Finally, stratification by sex of the outcomes of the analysis of the prevalence of symptoms did not show clear differences between boys and girls in response to air pollution.

Table 4 Combined OR (95\% CI) for $100 \mu \mathrm{g} / \mathrm{m}^{3}$ increase in air pollution on prevalence of cough and phlegm, in subjects selected only on cough and subjects selected on asthmatic symptoms

\begin{tabular}{|c|c|c|c|c|c|c|c|c|c|c|c|c|}
\hline & \multicolumn{6}{|c|}{ Phlegm } & \multicolumn{6}{|c|}{ Lower respiratory symptoms } \\
\hline & \multicolumn{2}{|c|}{$\overline{C O U G H^{-}}$} & \multicolumn{2}{|c|}{$A S T^{+}$} & \multicolumn{2}{|r|}{$A S T$} & \multicolumn{2}{|r|}{ COUGH } & \multicolumn{2}{|r|}{$A S T^{+}$} & \multicolumn{2}{|c|}{$A S T$} \\
\hline & $n^{*}$ & OR $(95 \% C I)$ & $n^{*}$ & OR $(95 \% C I)$ & $n^{\star}$ & OR $(95 \% C I)$ & $n^{*}$ & OR $(95 \% C I)$ & $n^{\star}$ & OR $(95 \% C I)$ & $n^{*}$ & OR $(95 \% C I)$ \\
\hline \multicolumn{13}{|l|}{$\mathrm{PM}_{10}$} \\
\hline Lag 0 & 22 & $1.02(0.87$ to 1.21$) \ddagger$ & 23 & $0.98(0.83$ to 1.17$) \ddagger$ & 25 & $0.95(0.85$ to 1.06$) \ddagger$ & 7 & $0.96(0.54$ to 1.70$) \ddagger$ & 24 & $0.87(0.75$ to 1.00$) \dagger$ & 22 & $1.00(0.84$ to 1.18$) \ddagger$ \\
\hline Lag 1 & 23 & $1.09(0.92$ to 1.29$) \ddagger$ & 24 & $1.04(0.92$ to 1.18$) \dagger$ & 25 & $1.03(0.94$ to 1.13$) \ddagger$ & 7 & $0.86(0.59$ to 1.26$) \dagger$ & 24 & $0.98(0.82$ to 1.18$) \ddagger$ & 22 & $1.06(0.90$ to 1.24$) \ddagger$ \\
\hline $\mathrm{Lag} 2$ & 23 & $0.97(0.79$ to 1.19$) \ddagger$ & 23 & $0.99(0.84$ to 1.16$) \ddagger$ & 25 & $0.97(0.87$ to 1.08$) \ddagger$ & 7 & $0.80(0.54$ to 1.18$)$ t & 24 & $0.91(0.76$ to 1.09$) \ddagger$ & 22 & $1.02(0.83$ to 1.24$) \ddagger$ \\
\hline 7 Day mean & 23 & $1.38(0.68$ to 2.81$) \ddagger$ & 23 & $1.14(0.66$ to 1.99$) \ddagger$ & 25 & $0.73(0.46$ to 1.15$) \ddagger$ & 7 & $0.96(0.13$ to 6.89$) \ddagger$ & 24 & $0.94(0.52$ to 1.70$) \ddagger$ & 22 & $0.80(0.51$ to 1.24$) \ddagger$ \\
\hline \multicolumn{13}{|l|}{ Black Smoke } \\
\hline Lag 0 & 23 & $1.09(0.93$ to 1.29$) \ddagger$ & 23 & $0.92(0.71$ to 1.18$) \ddagger$ & 25 & $0.99(0.90$ to 1.10$) \dagger$ & 7 & $0.79(0.43$ to 1.44$) \ddagger$ & 24 & $0.96(0.79$ to 1.16$) \dagger$ & 22 & $0.97(0.77$ to 1.23$) \ddagger$ \\
\hline Lag 1 & 23 & $1.07(0.85$ to 1.34$) \ddagger$ & 24 & $0.99(0.78$ to 1.24$) \ddagger$ & 25 & $1.12(0.98$ to 1.27$) \ddagger$ & 7 & $0.80(0.52$ to 1.24$) \dagger$ & 24 & $0.81(0.63$ to 1.04$) \ddagger$ & 22 & $0.94(0.74$ to 1.21$) \ddagger$ \\
\hline $\mathrm{Lag} 2$ & 23 & $1.02(0.83$ to 1.25$) \ddagger$ & 23 & $0.94(0.79$ to 1.12$) \dagger$ & 25 & $1.01(0.91$ to 1.11$) \dagger$ & 7 & $0.91(0.59$ to 1.41$) \dagger$ & 24 & $0.97(0.73$ to 1.28$) \ddagger$ & 22 & $1.00(0.82$ to 1.22$) \ddagger$ \\
\hline 7 Day mean & 22 & $2.02(0.84$ to 4.86$) \ddagger$ & 24 & $0.76(0.31$ to 1.84$) \ddagger$ & 25 & $0.52(0.27$ to 1.00$) \ddagger$ & 7 & $0.95(0.09$ to 9.53$) \ddagger$ & 24 & $0.94(0.39$ to 2.25$) \ddagger$ & 22 & $0.61(0.34$ to 1.11$) \ddagger$ \\
\hline \multicolumn{13}{|l|}{$\mathrm{SO}_{2}$} \\
\hline Lag 0 & 21 & $1.05(0.69$ to 1.61$) \ddagger$ & 21 & $0.92(0.68$ to 1.23$) \ddagger$ & 23 & $0.87(0.79$ to 0.96$) \dagger$ & 7 & $0.46(0.23$ to 0.93$) \dagger$ & 22 & $0.94(0.80$ to 1.10$) \dagger$ & 20 & $1.12(0.97$ to 1.30$)+$ \\
\hline Lag 1 & 21 & $0.92(0.74$ to 1.14$) \ddagger$ & 21 & $0.73(0.44$ to 1.22$) \ddagger$ & 23 & $0.99(0.85$ to 1.15$) \ddagger$ & 7 & $0.65(0.19$ to 2.22$) \ddagger$ & 22 & $1.04(0.75$ to 1.44$) \ddagger$ & 20 & $0.99(0.87$ to 1.14$) \dagger$ \\
\hline $\mathrm{Lag} 2$ & 21 & $0.88(0.70$ to 1.11$) \ddagger$ & 21 & $0.97(0.81$ to 1.17$) t$ & 23 & $0.94(0.79$ to 1.11$) \ddagger$ & 7 & $0.96(0.52$ to 1.77$) t$ & 22 & $0.80(0.58$ to 1.10$) \ddagger$ & 20 & $1.04(0.92$ to 1.19$)$ t \\
\hline 7 Day mean & 21 & $0.89(0.45$ to 1.74$) \ddagger$ & 22 & $0.58(0.28$ to 1.21$) \ddagger$ & 23 & $0.60(0.34$ to 1.06$) \ddagger$ & 7 & $0.31(0.09$ to 1.07$) \dagger$ & 22 & $1.42(0.57$ to 3.57$) \ddagger$ & 20 & $0.84(0.46$ to 1.55$) \ddagger$ \\
\hline \multicolumn{13}{|l|}{$\mathrm{NO}_{2}$} \\
\hline Lag 0 & 21 & $1.11(0.77$ to 1.60$) \ddagger$ & 23 & 1.07 (0.76 to 1.49$) \ddagger$ & 23 & $0.97(0.87$ to 1.08$) \dagger$ & 6 & $0.98(0.46$ to 2.07$) \ddagger$ & 23 & $1.03(0.78$ to 1.36$) \ddagger$ & 20 & $1.35(1.15$ to 1.58$) \dagger$ \\
\hline Lag 1 & 21 & $1.00(0.74$ to 1.37$) \ddagger$ & 23 & $0.92(0.63$ to 1.35$) \ddagger$ & 23 & $0.96(0.82$ to 1.12$) \ddagger$ & 6 & $1.09(0.60$ to 2.00$) \ddagger$ & 23 & $1.01(0.80$ to 1.28$) \dagger$ & 20 & $0.83(0.58$ to 1.17$) \ddagger$ \\
\hline $\mathrm{Lag} 2$ & 20 & $0.85(0.64$ to 1.14$) \ddagger$ & 23 & $0.99(0.77$ to 1.26$) \dagger$ & 23 & $1.08(0.92$ to 1.26$) \ddagger$ & 6 & $0.81(0.51$ to 1.28$) \dagger$ & 23 & $0.78(0.57$ to 1.06$) \ddagger$ & 20 & $0.87(0.63$ to 1.20$) \ddagger$ \\
\hline 7 Day mean & 21 & $4.37(1.08$ to 17.66$) \ddagger$ & 23 & $0.80(0.29$ to 2.22$) \ddagger$ & 23 & $0.56(0.26$ to 1.20$) \ddagger$ & 6 & $1.33(0.29$ to 6.09$) \dagger$ & 23 & $1.47(0.42$ to 5.14$) \ddagger$ & 20 & $0.28(0.08$ to 1.01$) \ddagger$ \\
\hline
\end{tabular}

${ }^{\star}$ Number of panel specific estimates; $†$ Fixed effects model; $¥$ Random effects model. 


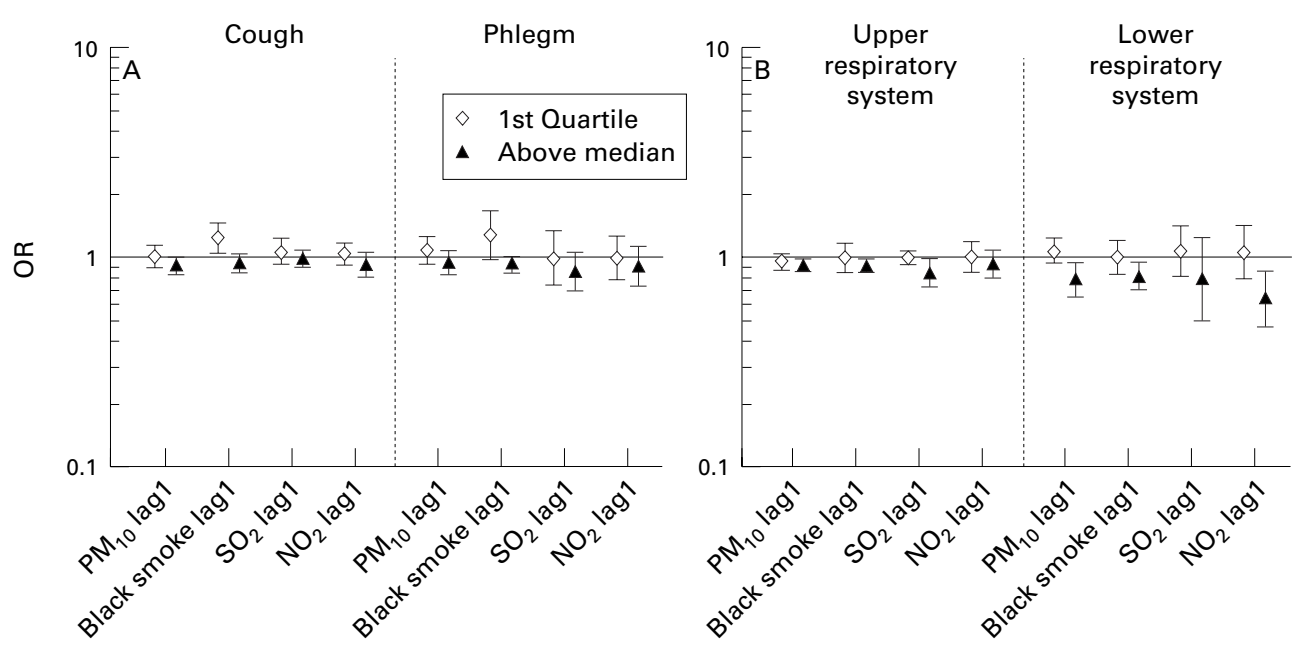

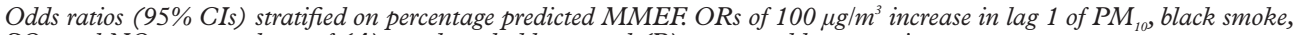
$\mathrm{SO}_{2}$, and $\mathrm{NO}_{2}$ on prevalence of $(A)$ cough and phlegm, and (B) upper and lower respiratory symptoms.

\section{Discussion}

Associations between air pollution and evening PEF tended to be negative in children selected on cough only. In asthmatic children who took respiratory medication, significant positive associations between air pollution and PEF were found. Asthmatic children who did not use medication did not show any association with air pollution. This pattern was not confirmed by the respiratory symptoms. In none of the subgroups was a consistent association with respiratory symptoms found. In children with atopy and children with a low lung function no air pollution effects on PEF and respiratory symptoms were found.

The stratification based on the selection questionnaire and use of medication showed that the association of air pollution on evening $\mathrm{PEF}$ in the $\mathrm{AST}^{+}$group was positive. An explanation might be that the children counteract the effects of air pollution on evening PEF by use of medication during the day. This is supported by the fact that in the groups not using respiratory medication the coefficients were less positive $\left(\mathrm{AST}^{-}\right.$) or even negative $\left(\mathrm{cough}^{-}\right)$and that the median coefficients are most positive in the centres with the highest mean daily prevalence of bronchodilator use. The fact that the prevalence of use of bronchodilators in the $\mathrm{AST}^{+}$group was not related to air pollution weakens this argument. However, it might be that children increased the daily dose of bronchodilator use, which is not reflected in the daily prevalence.

Negative associations between air pollution and evening PEF mainly occurred in the cough ${ }^{-}$group. The regression slope for $\mathrm{PM}_{10}$ lag 1 in the cough ${ }^{-}$group translates into a $-0.4 \%$ change of evening PEF associated with a $100 \mu \mathrm{g} / \mathrm{m}^{3}$ change in concentration, only slightly lower than the combined effect estimate of $-0.7 \%$ reported by Dockery and Pope ${ }^{18}$ Children with cough only differ in certain characteristics from the children with asthma. The mean daily prevalence of lower respiratory symptoms was lower in the cough ${ }^{-}$ group than in the other groups. An earlier analysis of the PEACE data showed that children selected only on cough had a lower variability in PEF than children selected for asthmatic symptoms. ${ }^{8}$ In the Finnish panels children selected on cough only had a lower prevalence of atopy and higher percentage of predicted $M M E F^{19}$ compared with children selected on asthmatic symptoms. By contrast with the outcome in this study, the children with asthma in the Finnish panels tended to react more strongly to air pollution than the children with cough only. ${ }^{5}$ This was also found in an earlier panel study in The Netherlands. ${ }^{4}$

In this study the difference in the effect of air pollution on morning PEF between the cough ${ }^{-}$ and the $\mathrm{AST}^{+}$groups was less pronounced than the effect on evening PEF. The morning PEF measurements were done after getting up and before taking medication and were preceded by a long period of exposure to indoor environmental factors. These exposures may have obscured the relatively weak signal of air pollution and at the same time the use of medication did not exert its counteracting effect in the $\mathrm{AST}^{+}$group. The difference in response is not reflected in the effect estimate of air pollution on symptom prevalence as the ORs were similar in the $\mathrm{AST}^{+}$, $\mathrm{AST}^{-}$, and cough ${ }^{-}$groups. These results differ from the results of the study by Peters $e t a l^{\beta}$ in which the children who used medication showed larger decrements in PEF and smaller ORs for prevalence of symptoms than children not using medication.

Stratification on sex, atopy, or lung function did not show consistent differences in the whole population between effect estimates of air pollution on PEF or symptom prevalence. Studies which showed a difference in response between boys and girls focused on chronic effects in the general population ${ }^{70}$ whereas the PEACE study was designed to study acute effects in children with symptoms.

One of the possible explanations of the lack of acute effects of fluctuations in daily concentrations of air pollutants on PEF or prevalence of symptoms and use of medication in the individual panels of PEACE was that subgroups of children within a panel biased the panel effect estimate towards the null or even in the oppo- 
site direction. ${ }^{21}$ On the basis of the results this explanation is unlikely for the analysis of prevalence of symptoms. The relation between PEF and air pollution differed between certain subgroups but still no clear effects of air pollution on PEF could be detected. Other possible explanations for this lack of effect are discussed elsewhere. ${ }^{21}$

This study did not show an effect of particulate air pollution on children's respiratory health. This might mean that there really was no association between particulate air pollution and children's respiratory health during the winter of 1993-4 and that in other studies which did show associations in panels of children ${ }^{124}$ the composition or level of air pollution was different, or that they had residual confounding. It might be that the exposure variables used in this study were not relevant for respiratory health. One hypothesis is that not the mass of particles but the number of ultrafine particles is of importance $e^{22}$ and that the correlation in time between ultrafine particle numbers and mass of $\mathrm{PM}_{10}$ is low. A panel study in Germany showed somewhat stronger health effects for particle numbers than for mass of $\mathrm{PM}_{10}{ }^{23}$ but in the Finnish PEACE panel this was not confirmed. ${ }^{24}$

In conclusion, none of the predefined potentially more sensitive subgroups showed consistent associations between air pollution, PEF, and respiratory symptoms. In children with asthma who used respiratory medication, significant positive associations between air pollution and PEF were found. Children with asthma who did not take medication did not show any association with air pollution.

The PEACE study was funded within the framework of the Commission of the European Communities environmen programme, contracts EV5V-CT92-0220, CIPD-CT-92-5052 and ERBCIPD-CT-93-0046. The Finnish, Norwegian and two Swedish centres were funded by grants from the respective governments. The study was coordinated by the Department of Environmental Sciences, Environmental and Occupational Health Group, Agricultural University Wageningen, PO Box 238, 6700 AE Wageningen, The Netherlands.

\section{Appendix}

The PEACE study is a collaboration of 14 European centres: Amsterdam (the Netherlands), Kuopio (Finland), Oslo (Norway), Berlin and Hettstedt (Germany), Pisa (Italy), Athens (Greece), Cracow and Katowice (Poland), Prague and Teplice (Czech Republic), Budapest (Hungary), and Umeå and Malmö (Sweden). 1 Pope CA III, Dockery DW, Spengler JW, et al. Respiratory
health and PM PM $_{10}$ pollution: a daily time series analysis. $\mathrm{Am}$ Rev Respir Dis 1991;144:668-74.
2 Pope CA III, Dockery DW. Acute health effects of $\mathrm{PM}_{10}$ pollution on symptomatic and asymptomatic children. $\mathrm{Am}$ Rev Respir Dis 1992;145:1123-8.

3 Peters A, Dockery DW, Heinrich J, et al. Medication use modifies the health effects of particulate sulfate air pollution in children with asthma. Environ Health Perspect $1997 ; 105 ; 430-5$.

4 Roemer W, Hoek G, Brunekreef B. Effect of ambient winter air pollution on respiratory health of children with chronic air pollution on respiratory health of children with chronic 24 .

5 Timonen K, Pekkanen J. Air pollution and respiratory health among children with asthmatic or cough symptoms. Am Rev Respir Dis 1997;156:546-52.

6 Pershagen G, Rylander E, Norberg S, et al. Air pollution involving nitrogen dioxide exposure and wheezing bronchitis in children. International fournal of epidemiology 1995;24: $1147-53$.

7 Brunekreef B, Janssen NAH, Hartog J de, et al. Air pollution from track traffic and lung function in children living near motorways. Epidemiology 1997;8:298-303.

8 Timonen KL, Nielsen J, Schwartz J, et al. Chronic respiratory symptoms, skin prick tests results and lung function as predictors of peak flow variability. Am J Respir Crit Care Med 1997;156:776-82.

9 Timonen KL, Nielsen J, Schwartz J, et al. Chronic respiratory symptoms, skin prick test results, and spirometric lung function as predictors of peak flow variability. $\mathrm{Am}$ 7 Respir Crit Care Med 1997;155(suppl):A78.

10 Roemer W, Hoek G, Brunekreef B, et al. Daily variations in air pollution and respiratory health in a multicenter study: the PEACE project. Eur Respir $\mathcal{F}$ (in press).

11 Roemer W, Hoek G, Brunekreef B, et al. Effect of short-term changes in urban air pollution on the respiratory health of children with chronic respiratory symptoms: The PEACE project: Introduction. European Respiratory Review 1998;8: $4-11$.

12 Quanjer PH. Standardized lung function testing. Bull Europ Physiopathol Resp 1983;19(suppl):1-95.

13 Quanjer PH, Tammeling GJ, Cotes JE, et al. Standardized lung function testing. Eur Respir f 1993;6(suppl 16):5-40.

4 Quanjer PH, Stocks J, Polgar G, Wise M, Karlberg J, Borsboom $\mathrm{G}$. Compilation of reference values for lung function measurements in children. Eur Respir f 1989;2(suppl 4): $184 \mathrm{~s}-261$.

15 Hoek G, Forsberg B, Borowska M, et al. Wintertime PM and black smoke concentrations across Europe: results from the PEACE study. Atmospheric Environment 1997;31: 3609-22.

16 Kleinbaum DG, Kupper LL, Muller KE. Applied regression analysis and other multivariate methods. Belmont, California: Duxbury Press, 1988:200-1.

17 DerSimonian R, Laird N. Meta-analysis in clinical trials. Control Clin Trials 1986;7:177-88.

18 Dockery DW, Pope CA III. Acute respiratory effects of particulate air pollution. Annu Rev Public Health 1994;15:10732

19 Timonen KL, Pekkanen J, Korppi M, et al. Prevalence and characteristics of children with chronic respiratory symptoms in eastern Finland. Eur Respir F 1995;8:1155-60.

20 Oosterlee A, Drijver M, Lebret E, et al. Chronic respiratory symptoms in children and adults living along streets with high traffic density. Occup Environ Med 1996;53:241-7.

21 Roemer W, Hoek G, Brunekreef B, et al. The PEACE project: general discussion. European Respiratory Review $1998 ; 8: 52,125-30$.

22 Seaton A, MacNee W, Donaldson K, et al. Particulate air pollution and acute health effects. Lancet 1995;345:17678

23 Peters A, Wichmann HE, Tuch T, et al. Respiratory effects are associated with the number of ultrafine particles. $A m \mathcal{F}$ Respir Crit Care Med 1997;155:1376-83.

24 Pekkanen J, Timonen KL, Ruuskanen J, et al. Effects of ultrafine and fine particles in urban air on peak expiratory flow among children with asthmatic symptoms Environ Res 1997;74:24-33. 